\title{
Effect of Necrosis on the miRNA-mRNA Regulatory Network in CRT-MG Human Astroglioma Cells
}

\author{
So-Hee Ahn, PhD ${ }^{1,2}$ \\ Jung-Hyuck Ahn, PhD2,3 \\ Dong-Ryeol Ryu, MD, PhD24 \\ Jisoo Lee, MD, $\mathrm{PhD}^{4}$ \\ Min-Sun Cho, MD, PhD \\ Youn-Hee Choi, MD, PhD ${ }^{1,2}$
}

${ }^{1}$ Department of Physiology, ${ }^{2}$ Tissue Injury Defense Research Center, Departments of ${ }^{3}$ Biochemistry, Internal Medicine, and ${ }^{5}$ Pathology, Ewha Womans University School of Medicine, Seoul, Korea
Correspondence: Youn-Hee Choi, MD, PhD

Department of Physiology, Ewha Womans

University School of Medicine,

1071 Anyangcheon-ro, Yangcheon-gu,

Seoul 07985, Korea

Tel: 82-2-2650-5838

Fax: 82-2-2650-5717

E-mail: yc@ewha.ac.kr

Received November 22, 2016

Accepted April 25, 2017

Published Online May 22, 2017

\begin{abstract}
Purpose
Glioblastoma multiforme (GBM) is the most common adult primary intracranial tumor. The remarkable features of GBM include central necrosis. MicroRNAs (miRNAs) have been considered as diagnostic/prognostic biomarkers for many cancers, including glioblastoma. However, the effect of necrosis on the miRNA expression profile and predicted miRNA-mRNA regulatory information remain unclear. The purpose of this study is to examine the effect of necrotic cells on the modulation of miRNA and mRNA expression profiles and miRNA-mRNA network in CRT-MG cells.
\end{abstract}

\section{Materials and Methods}

We used human astroglioma cells, CRT-MG, treated with necrotic CRT-MG cells to examine the effect of necrosis on the modulation of miRNA and mRNA by next-generation sequencing. For preparation of necrotic cells, CRT-MG cells were frozen and thawed through cycle of liquid nitrogen-water bath. The putative miRNA-mRNA regulatory relationship was inferred through target information, using miRDB.

\section{Results}

The necrotic cells induced dysregulation of 106 miRNAs and 887 mRNAs. Among them, 11 miRNAs that had a negative correlation value of $p<0.05$ by the hypergeometric test were screened, and their target mRNAs were analyzed by Gene Ontology enrichment analysis. Using the Kyoto Encyclopedia of Genes and Genomes database, we also found several necrotic cell treatment-activated pathways that were modulated by relevant gene targets of differentially expressed miRNAs.

\section{Conclusion}

Our result demonstrated that dysregulation of miRNA and mRNA expression profiles occurs when GBM cells are exposed to necrotic cells, suggesting that several miRNAs may have the potential to be used as biomarkers for predicting GBM progression and pathogenesis.

\section{Introduction}

Grade IV astrocytoma, also called glioblastoma multiforme (GBM), is considered the most aggressive and malignant form of glial tumors [1]. The remarkable features of GBM include diffused infiltration into normal brain parenchyma, local invasion, angiogenesis, and the presence of necrotic tissues $[2,3]$. Results obtained from clinical studies show that necrosis has an overall negative impact on patient survival
Key words

Glioblastoma, Necrosis, MicroRNA and is linked to a poor prognosis [4]. Our group has demonstrated that necrosis enhances glioblastoma cell migration and invasion [5]. Despite extensive treatments, including surgery, radiotherapy, chemotherapy, immunotherapy, and symptomatic therapy, the median survival for patients with GBM is $12-15$ months [6]. Because of the poor overall patient survival, the search for new molecular targets and prognostic indicators is of particular interest in GBM research.

A microRNA (miRNA) is a noncoding, interfering RNA with a length of approximately 22-25 nucleotides. It is capa- 
ble of binding to the $3^{\prime}$ untranslated region of its target mRNA, resulting in mRNA cleavage and negative post-transcriptional regulation of target gene expression [7]. The decrease of suppressive miRNAs on oncogenes and the increase of inhibitory miRNAs on tumor suppressors control gene expression and play specific roles in cancer cell predisposition and initiation, proliferation, invasion, angiogenesis, inflammation, and metastasis in breast cancer, prostate cancer, nasopharyngeal carcinoma, and glioblastoma [8-12]. Therefore, miRNAs are considered prognostic indicators and potential alternative therapeutic targets for many cancers, including glioblastoma [13-15].

Dysregulation of miRNAs is frequently observed in patients with GBM [16]. Previous studies have demonstrated that numerous miRNAs play a role in both the tumorigenesis and recurrence of GBM through their modulation of several cancer-related genes, such as those encoding proliferation, invasion, radiosensitivity and chemosensitivity, and angiogenesis [8,17-19]. Although numerous efforts have been devoted to the establishment of miRNA-based prognostic and diagnostic biomarkers for predicting the progression of GBM, the molecular profiling of glioblastomas with or without necrosis has not yet been clearly demonstrated.

In this study, we investigated the effect of necrotic cells on the miRNA and mRNA expression profiles as well as the negative miRNA-mRNA correlations in a human astroglioma cell line, CRT-MG. Using next-generation sequencing (NGS) analysis, we profiled the miRNA and mRNA expression levels in CRT-MG cells with or without necrotic cell treatment. The miRNAs and mRNAs showing significant changes were selected, and integrative miRNA-mRNA network analyses were performed.

\section{Materials and Methods}

\section{Cells}

Human astroglioma CRT-MG cells were maintained in Dulbecco's modified essential medium (cat. LM001-05, WelGENE Inc., Daegu, Korea) containing 10\% fetal bovine serum (Gibco, Grand Island, NY), L-glutamine, $100 \mathrm{U} / \mathrm{mL}$ penicillin and $10 \mu \mathrm{g} / \mathrm{mL}$ streptomycin. For preparation of the necrotic cells, CRT-MG cells were subjected to five frozen-thaw cycles of liquid nitrogen-water bath treatment to induce a necrotic state in the cells [20]. CRT-MG cells that were not treated with the necrotic cells were used as controls.

\section{RNA extraction and NGS}

Total cellular RNA was isolated from cells using an RNA extraction kit (Qiagen, Hilden, Germany) according to the manufacturer's protocol. Small RNA sequencing was done on the Illumina Hiseq 2500 platform (Illumina, San Diego, CA), using 51-bp single-end sequencing with a fragment size of 145-160 bp. The TruSeq small RNA Library Prep kit (Illumina) was used for preparing the library. To detect known and novel miRNAs, unique clustered reads were aligned with the reference genome as well as with precursor miRNAs obtained from miRBase v.21. The miRDeep2 algorithm was used to predict potential hairpin structures and to assign scores that represented the probability that hairpins were true miRNA precursors. The read counts for each miRNA were extracted from mapped miRNAs to report the abundance of each miRNA. To filter differentially expressed miRNAs, the reads for each miRNA were normalized to the total reads of each individual sample, standardized as the read per kilobase of transcript per million mapped reads (RPKM). MiRNAs with a median fold change of $|\mathrm{fc}| \geq 2$ were considered meaningful. An mRNA sequencing was done on the Illumina HiSeq 2000 platform, using 101-bp paired-end sequencing with a fragment size of 200-400 bp. The TruSeq RNA kit was used for preparing the library. Samples with the desired minimum of 5 GB mapped and properly paired read pairs from any standard mapper were chosen, without filtering for mapping quality. The mRNAs with expression profiles that differed between the samples were normalized as fragments per kilobase of transcript per million mapped reads. An mRNA with was $\mathrm{fc} \leq-2$ was considered downregulated whereas that with $\mathrm{fc} \geq 2$ was considered upregulated.

\section{Primary glioblastoma tissues}

Human glioblastoma tissue specimen was selected from the Department of Pathology, Ewha Womans University Mokdong Hospital, over the past 3 years (2012-2014). Hematoxylin-eosin-stained slides were reviewed and all cases showed variable degree of geographic necrosis. This study protocol was approved by the Institutional Review Board (IRB) of the Ewha Womans University Mokdong hospital (IRB protocol number: EUMC 2016-01-005). Informed consent had been obtained from each patient prior to surgery and was waived in this study by IRB due to the retrospective nature. Small RNA was isolated from formalin-fixed, paraffin-embedded (FFPE)-GBM tissues including the near-necrosis tumor area and non-necrosis tumor area using an exosomal miRNA purification kit (Genolution, Seoul, Korea) according to the manufacturer's protocol. 
Table 1. List of primer sequences used for RT-PCR and qRT-PCR analysis

\begin{tabular}{|c|c|c|c|}
\hline & \multicolumn{2}{|c|}{ Gene (human) } & Sequence \\
\hline \multirow[t]{20}{*}{ RT-PCR primer } & CXCL3 & Forward & 5'-ATGGCCCACGCCACGCTCTCCG-3' \\
\hline & & Reverse & 5'-TCAGTTGGTGCTCCСCTTGTTC-3' \\
\hline & CCL2 & Forward & 5'-ATGAAAGTCTCTGCCGCCCTTCTGT-3' \\
\hline & & Reverse & 5'-AGTCTTCGGAGTTTGGGTTTGCTTG-3' \\
\hline & $1 L 1 A$ & Forward & 5'-GTAAGCTATGGCCCACTCCA-3' \\
\hline & & Reverse & 5'-AGGTGCTGACCTAGGCTTGA-3' \\
\hline & TNIP1(6) & Forward & 5'-GTTGCTGAAACAGCAGGTGA-3' \\
\hline & & Reverse & 5'-GAGGCCTTTGCTTTCСТCTT-3' \\
\hline & TNIP1(10) & Forward & 5'-AAGACCСССТTССТTСАAАA-3' \\
\hline & & Reverse & 5'-GATGGCTTCAGCAAGGCTAC-3' \\
\hline & ALOX5AP & Forward & 5'-TGGGGTTGGTGTTCTCATCT-3' \\
\hline & & Reverse & 5'-ACCTGGTCACAAAACATCTTCAG-3' \\
\hline & CYBRD1 & Forward & 5'-CCATCCATGCAGGGTTAAATG-3' \\
\hline & & Reverse & 5'-CCAACCCAGCTGTGCAGACT-3' \\
\hline & COL2A1 & Forward & 5'-CGTCCAGATGACCTTCCTACG-3' \\
\hline & & Reverse & 5'-TGAGCAGGGCCTTCTTGAG-3' \\
\hline & CNR1 & Forward & 5'-GAAAGCTGCATCAAGAGCAC-3' \\
\hline & & Reverse & 5'-TTTTCCTGTGCTGCCAGGG-3' \\
\hline & GAPDH & Forward & 5'-GGAGCCAAAAGGGTCATCAT-3' \\
\hline & & Reverse & 5'-GTGATGGCATGGACTGTGGT-3' \\
\hline \multirow[t]{12}{*}{ qRT-PCR primer } & ICAM1 & Forward & 5'-AATTCCCAGACTCCAATG-3' \\
\hline & & Reverse & 5'-AGGCGTGGCTTGTGTGTTCGG-3' \\
\hline & LCN2 & Forward & 5'-GGTAGGCCTGGCAGGGAATG-3' \\
\hline & & Reverse & 5'-CTTAATGTTGCCCAGCGTGAAC-3' \\
\hline & POSTN & Forward & 5'-ATTCCTGATTCTGCCAAACAAG-3' \\
\hline & & Reverse & 5'-AGAAAATGCATTATTCACAGGT-3' \\
\hline & PCP4 & Forward & 5'-AGAGCCAACATGAGTGAGCGA-3' \\
\hline & & Reverse & 5'-TGGTGCATCCATGTCAATGTC-3' \\
\hline & LYPD1 & Forward & 5'-TTGCGGATTGTTCTTGCTTCCAGG-3' \\
\hline & & Reverse & 5'-TGATGATGCACAGGACTTGCGGTA-3' \\
\hline & GAPDH & Forward & 5'-GGAGCCAAAAGGGTCATCAT-3' \\
\hline & & Reverse & 5'-GTGATGGCATGGACTGTGGT-3' \\
\hline
\end{tabular}

RT-PCR, reverse transcription-polymerase chain reaction; qRT-PCR, quantitative reverse transcription-polymerase chain reaction.

\section{Reverse transcription-polymerase chain reaction}

cDNA was synthesized from $1 \mu \mathrm{g}$ of total RNA with reverse transcription (MLV-RT, Enzynomics, Daejeon, Korea) and polymerase chain reaction (PCR) was performed $3 \mu \mathrm{L}$ cDNA with a thermal cycler (Bio-Rad Laboratories, Hercules, CA). The mRNA levels were determined using G-Taq DNA polymerase, 10× Taq buffer and $2.5 \mathrm{mM}$ dNTP (LaboPass, COSMO Genetech, Seoul, Korea). Primer sequences are listed in Table 1. Each PCR samples were visualized on 1\% agarose gels stained with GelRed (Biotium Inc., Hyward, CA).

\section{Quantitative reverse transcription-polymerase chain} reaction

Quantitative reverse transcription-polymerase chain reaction (qRT-PCR) was performed on an ABI Step One Plus Real-Time PCR machine (Applied Biosystems, Foster City, CA) using a Power SYBR Green PCR Master Mix (Applied Biosystems) according to the manufacturer's protocol. Primer sequences are listed in Table 1. Quantitation approach was performed by termed the comparative $\mathrm{Ct}$ method as previously described [21]. The Ct values of both the control and the samples of interest are normalized to an appropriate GAPDH gene. Relative expression levels were calculated as 
$2^{-\Delta \Delta C \mathrm{t}}$ method, where $\Delta \Delta \mathrm{Ct}=$ target gene sample $\Delta \mathrm{Ct}$-target gene control $\Delta \mathrm{Ct}$.

\section{6. miRNA-mRNA integrative genomic analysis}

For identification of the candidate miRNA-mRNA network, three separate steps were carried out. First, miRNAs and mRNAs with differential expression were extracted though the differentially expressed gene and differentially expressed miRNA list, with significant cut-offs miRNA | fc | $\geq 2$ and mRNA $\left|f_{c}\right| \geq 2$ in the miRNA and mRNA data set. Second, the putative miRNA-mRNA regulatory relationship was inferred through target information, using miRDB (v.5.0; http://mirdb.org/miRDB/ ). Finally, the negative correlation between the miRNA and mRNA expression profiles was confirmed.

\section{Functional analysis}

Based on the miRNA-mRNA integrative genomic analysis, we identified biological themes for each negatively correlated miRNA-mRNA pair using Gene Ontology (GO) (http://geneontology.org/). GO provides annotation terms that are arranged hierarchically in three namespaces that describe different aspects of a protein's function: molecular function, biological process, and cellular component (http:// geneontology.org/page/ontologydocu mentation) [22]. Pathway analysis of negative miRNA-mRNA correlations was mapped to the Kyoto Encyclopedia of Genes and Genomes (KEGG) database (http://www.kegg.jp/kegg/ pathway.html). KEGG includes a pathway database with computerized knowledge on molecular interaction networks, such as pathways and complexes. The p-value was calculated for each enriched pathway [23].

\section{Statistical analysis}

The mean \pm standard error of the mean from two independent experiments is shown in all bar graphs. Statistical significance was analyzed with Student's t test, using the program R Statistical Language v.3.1.2 (Institute for Statistics and Mathematics, Vienna, Austria). Statistical significance of the data was set at a value of $\mathrm{p}<0.05$.

\section{Results}

\section{Differentially expressed miRNAs between necrotic cell- treated and untreated CRT-MG cells}

To test whether necrotic tissues affect the miRNA-mRNA regulatory network in GBM, CRT-MG cells were either untreated or treated with necrotic cells and mature miRNAs and mRNA were quantitatively analyzed using NGS. Necrotic CRT-MG cells were prepared by freezing/thawing methods as described previously and confirmed by flow cytometry revealed that more than $90 \%$ of prepared cells were propidium iodide-positive [5]. The expression of mature miRNAs using small RNA sequencing. Of the 2,588 mature miRNAs detected in the analysis, 1,908 with at least one zero raw signal (RPKM) were excluded and 680 mature miRNAs for further analysis. Compared with untreated cells, the treated CRT-MG cells showed dysregulation of 106 miRNAs that had significantly different expression levels with 2-fold change as a cut off (Fig. 1A). Of these 106 miRNAs, 55 were upregulated (52\%) and 51 were downregulated (48\%) in the treated cells (Fig. 1B). The top five mature miRNAs are marked in the scatter plot; miR-4792, miR-146a-5p, and miR-155-5p were upregulated, and miR-let-7e-5p and miR-let-7c-5p were downregulated (Fig. 1C). The top 20 of the 55 upregulated miRNAs and the top 20 of the 51 downregulated miRNAs, as well as miRNAs matched to previous studies that have been previously reported in GBM are summarized in Table 2 [24-27]. To explore whether miRNA expression is altered in primary GBM tissues, we performed qRT-PCR for four miRNAs using FFPE glioblastoma patient samples. In miRNA real-time PCR analysis using primary GBM tissues, we observed similar finding that followed the sequencing trend in CRT-MG cells, showing increased miR-3656 and decreased miR-874-5p expression in perinecrotic region compared to non-necrosis tumor tissues (Fig. 1D).

\section{Differentially expressed mRNAs between necrotic cell- treated and untreated CRT-MG cells}

Next, we investigated the expression patterns of mRNAs using transcriptome resequencing. Of the 25,906 genes detected, 7,475 with at least one zero raw signal (fragments per kilobase of transcript per million mapped reads [FPKM]) were excluded, leaving 18,431 genes to be further analyzed. These mRNA expression profiles revealed significant dysregulation of 887 mRNAs in the treated CRT-MG cells (Fig. 2A). We further found differences in the classification of mRNAs in the treated cells relative to the untreated cells. As shown in Fig. 2B, 508 mRNAs were upregulated (57\%), whereas 379 mRNAs were downregulated (43\%), after incubation with 
A
Color key

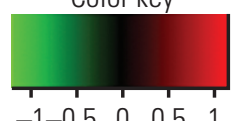

$-1-0.5 \quad 0 \quad 0.5 \quad 1$
Row Z-score
Heat map of the two-way hierarchical clustering

(106 mature_miRNAs satisfying with fc2)

using Z-score for normalized value ( $\log _{2}$ based)

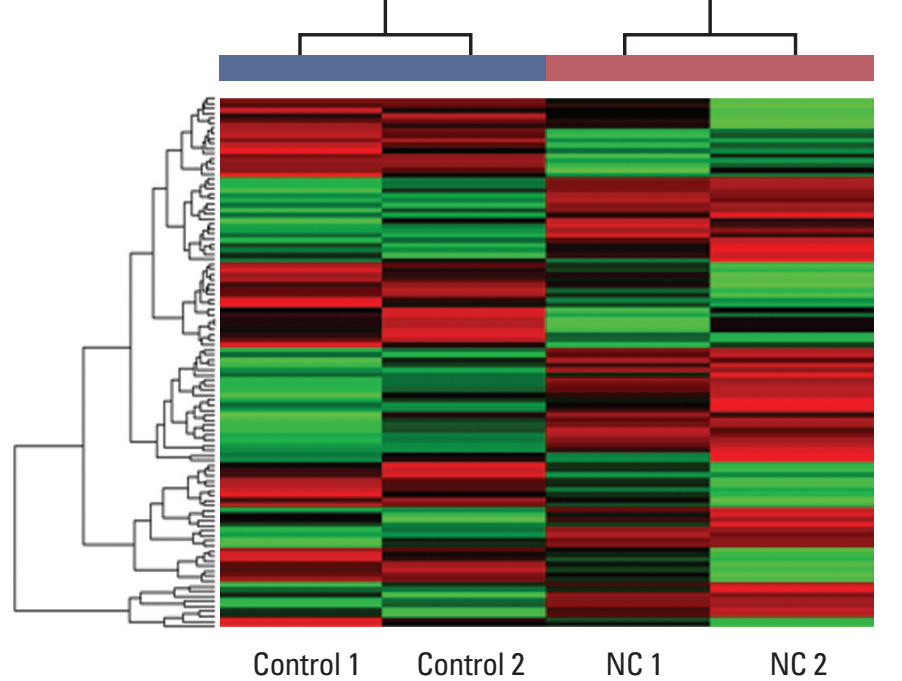

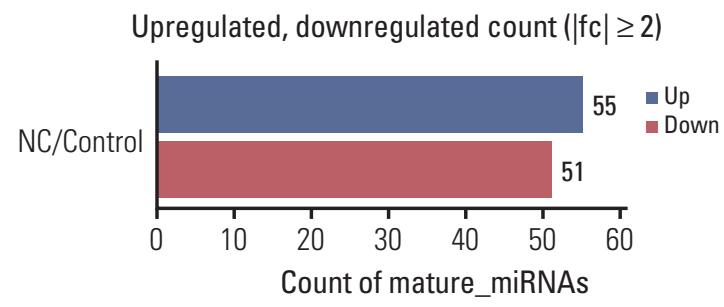

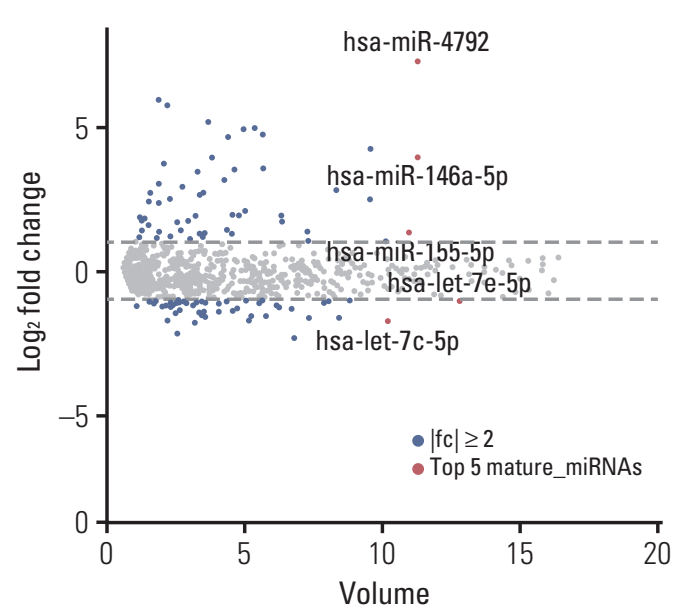

C
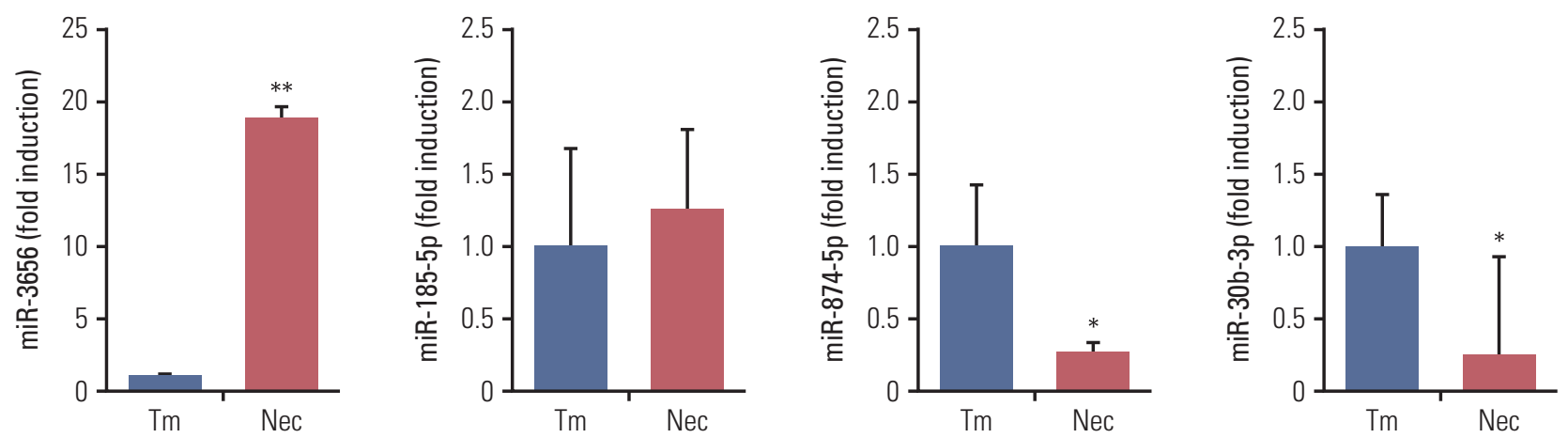

Fig. 1. Graphical representation of the 106 miRNAs differentially expressed between necrotic cell-treated and untreated CRT-MG cells. (A) Clustering of the 106 most differentially upregulated and downregulated miRNAs for classification between the necrotic cell-treated (NC) and untreated CRT-MG cells (control). Complete linkage hierarchical clustering was performed with the Euclidian distance measure. The NC and control cells clustered separately. The colors in the heat map represent the normalized expression values, with lower expression values being colored in shades of green and higher expression values in shades of red. (B) Counts of mature miRNAs upregulated or downregulated in NC cells. (C) Scatter plot showing the normalized miRNA volume of all conditions analyzed (y-axis) and changes in miRNAs expression between the NC and control cells. The top five most significantly dysregulated miRNAs are marked. (D) Quantitative real-time polymerase chain reaction analysis was performed glioblastoma multiforme tissues from the near-necrosis tumor area (Nec) and from non-necrosis tumor area $(\mathrm{Tm})$. Data are presented as fold induction compared with non-necrosis tumor area. ${ }^{*} \mathrm{p}<0.05,{ }^{* *} \mathrm{p}<0.01$ vs. Tm. 
Table 2. The top 20 most differentially upregulated and downregulated miRNAs in necrotic cell-treated CRT-MG cells

\begin{tabular}{|c|c|c|c|}
\hline & Mature miRNA & Fold change & GBM \\
\hline \multirow[t]{20}{*}{ Upregulated miRNAs (top 20 out of 55) } & hsa-miR-4792 & 149.29 & - \\
\hline & hsa-miR-3609 & 60.73 & - \\
\hline & hsa-miR-4466 & 53.21 & - \\
\hline & hsa-miR-4516 & 36.09 & - \\
\hline & hsa-miR-7704 & 30.79 & - \\
\hline & hsa-miR-3648 & 29.92 & - \\
\hline & hsa-miR-3960 & 26.37 & - \\
\hline & hsa-miR-4461 & 24.66 & - \\
\hline & hsa-miR-6087 & 18.66 & - \\
\hline & hsa-miR-663a & 15.27 & - \\
\hline & hsa-miR-146a-5p & 15.11 & [24] \\
\hline & hsa-miR-4488 & 13.10 & - \\
\hline & hsa-miR-1246 & 11.47 & [25] \\
\hline & hsa-miR-3656 & 11.41 & - \\
\hline & hsa-miR-4508 & 10.69 & - \\
\hline & hsa-miR-4485-3p & 8.88 & - \\
\hline & hsa-miR-4492 & 8.02 & - \\
\hline & hsa-miR-1290 & 7.52 & - \\
\hline & hsa-miR-7641 & 6.99 & - \\
\hline & has-miR-619-5p & 6.52 & - \\
\hline \multirow[t]{20}{*}{ Downregulated miRNAs (top 20 out of 51) } & hsa-miR-4454 & -5.22 & - \\
\hline & hsa-miR-135a-3p & -4.63 & - \\
\hline & hsa-miR-5100 & -3.56 & - \\
\hline & hsa-miR-23a-5p & -3.40 & [26] \\
\hline & hsa-let-7c-5p & -3.36 & - \\
\hline & hsa-miR-874-5p & -3.34 & - \\
\hline & hsa-miR-486-3p & -3.15 & - \\
\hline & hsa-miR-1249-3p & -3.10 & - \\
\hline & hsa-miR-125b-2-3p & -3.09 & - \\
\hline & hsa-miR-196a-3p & -3.06 & - \\
\hline & hsa-miR-7977 & -3.01 & - \\
\hline & hsa-miR-26a-2-3p & -2.99 & - \\
\hline & hsa-miR-6500-3p & -2.82 & [27] \\
\hline & hsa-miR-33b-3p & -2.76 & - \\
\hline & hsa-miR-99a-3p & -2.73 & - \\
\hline & hsa-miR-509-3p & -2.73 & - \\
\hline & hsa-miR-3180 & -2.70 & - \\
\hline & hsa-miR-3180-3p & -2.70 & - \\
\hline & hsa-miR-1468-5p & -2.63 & - \\
\hline & hsa-miR-27b-5p & -2.56 & - \\
\hline
\end{tabular}

GBM, glioblastoma multiforme.

necrotic cells. The top five genes are indicated in the scatter plot; IL32, MT2A, and FTH1 were upregulated, and KRT18 and KRT8 were downregulated in the treated cells (Fig. 2C). The top 20 most differentially upregulated and downregulated mRNAs in the treated cells, and the mRNAs matched to existing reports about GBM, are shown in Table 3 [28-50]. We also utilized reverse transcription-polymerase chain reaction (RT-PCR) and qRT-PCR for direct validation of differential expression of mRNA in necrotic cell treated and untreated CRT-MG cells (Fig. 2D and E). 
A

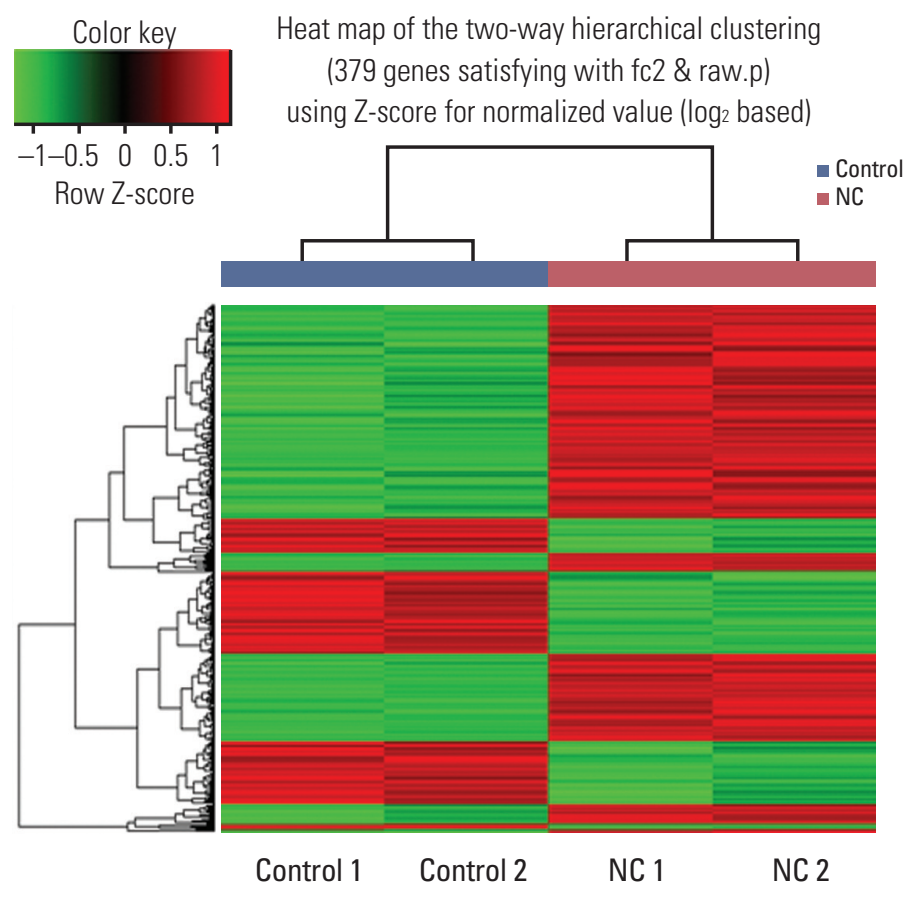

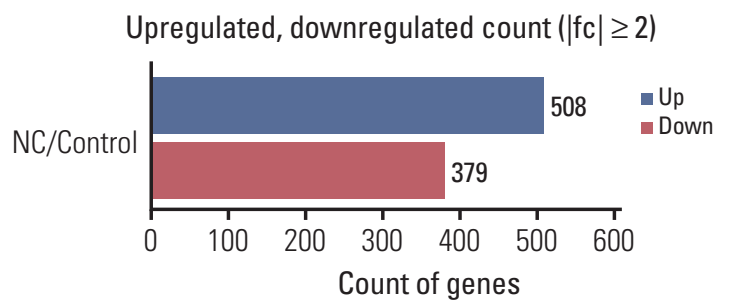

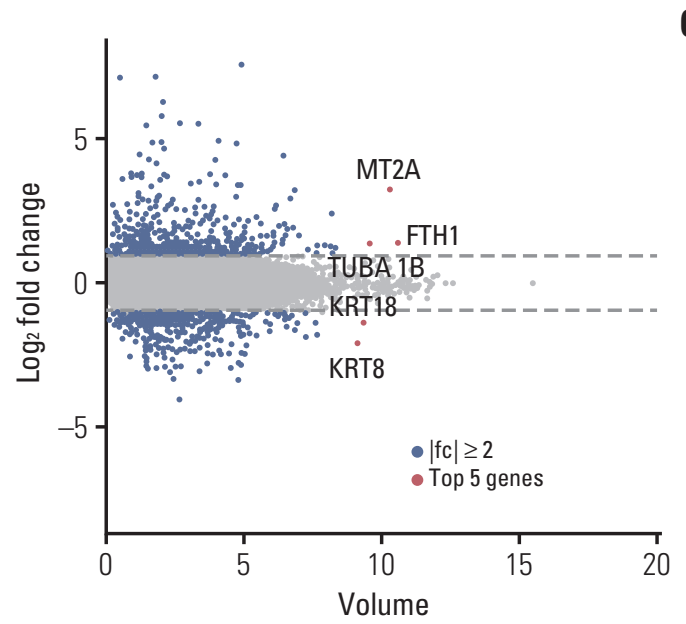

Fig. 2. Graphical representation of the $887 \mathrm{mRNAs}$ differentially expressed between necrotic cell-treated (NC) and untreated CRT-MG cells. (A) Clustering of the 887 most differentially upregulated and downregulated mRNAs for classification between the NC and untreated CRT-MG cells (control). Complete linkage hierarchical clustering was performed with the Euclidian distance measure. The NC and control cells clustered separately. The colors in the heatmap represent the normalized expression values, with lower expression values being colored in shades of green and higher expression values in shades of red. (B) Counts of mRNAs upregulated or downregulated in NC cells. (C) Scatter plot showing the normalized mRNA volume of all conditions analyzed (y-axis) and changes in mRNA expression between the NC and control cells. The top five most significantly dysregulated genes are marked. (Continued to the next page)

\section{Integrative genomic analysis of negative miRNA-mRNA correlations in necrotic cell-treated CRT-MG cells}

To understand the potential functions of the significant differentially expressed miRNAs, and to further explore miRNAmRNA regulatory information in the treated cells, we performed an analysis of the gene expression data to identify genes that were inversely co-expressed with an miRNA, as well as analysis of the target prediction that was used to identify genes containing binding sites of an miRNA. The 106 mature miRNAs and 887 validated mRNAs that were differentially expressed in the treated CRT-MG cells were analyzed by searching all the miRNAs in the miRDB v5.0 database (mirBase rel.21). Consequently, 88 miRNAs were found to have at least one negatively regulated miRNA-mRNA pair for significant mRNAs, and 11 miRNAs a negative correlation with $\mathrm{p}<0.05$ by the hypergeometric test (Table 4 ). The upregulated miRNA-downregulated mRNA and downregulated miRNAupregulated mRNA pairs in necrotic cell-treated CRT-MG cells with $\mathrm{p}<0.05$ by the hypergeometric test are shown in Fig. 3. Detailed information about each miRNA-mRNA integrative genomic analysis is shown in Table 5 .

\section{Function annotation and pathways affected by relevant negative miRNA-mRNA correlations in necrotic cell-treated CRT-MG cells}

In order to study the regulatory effects of the significant negatively correlated miRNA-mRNA pairs, and to further explore the function of the predicted target genes, 188 genes that were significantly $(\mathrm{p}<0.05)$ upregulated and downregulated in the treated CRT-MG cells were selected for mapping into the 

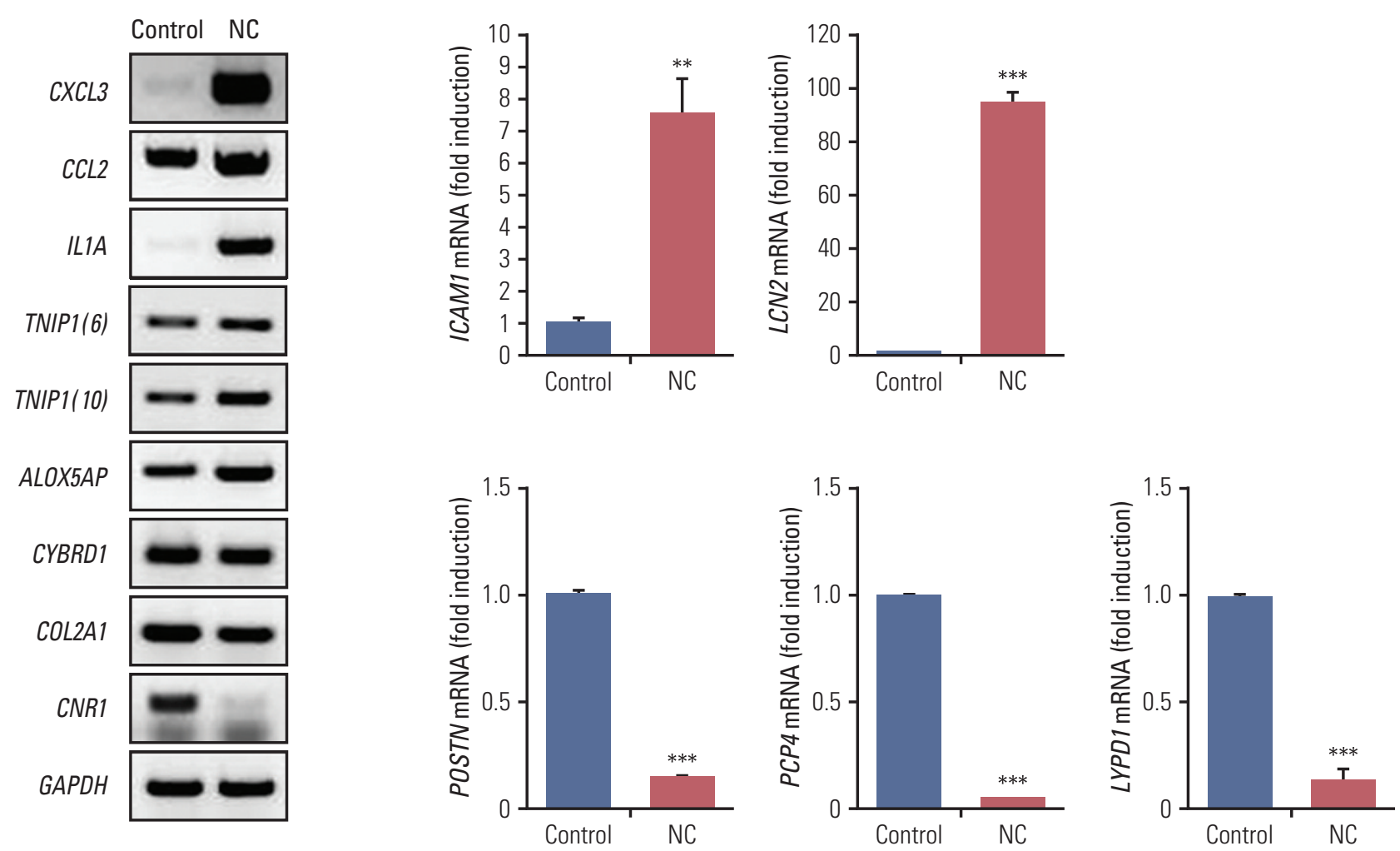

Fig. 2. (Continued from the previous page) (D, E) Validation of mRNA analyzed reverse transcription-polymerase chain reaction (RT-PCR) and quantitative reverse transcription-polymerase chain reaction (qRT-PCR). (D) The expression level of six upregulated mRNA (CXCL3, CCL2, IL1A, TNIP1 [transcript variant 6 and 10], and ALOX5AP) and three downregulated mRNA (CYBRD1, COL2A1, and CNR1) were validated by RT-PCR. GAPDH gene was evaluated as external control. (E) Two upregulated mRNA (ICAM1 and LCN2) and three downregulated mRNA (POSTN, PCP4, and LYPD1) were determined by qRT-PCR. Data are presented as fold induction compared with untreated necrotic cells. ${ }^{* *} \mathrm{p}<0.01,{ }^{* * *} \mathrm{p}<0.001$ vs. control.

DAVID database and subjected to functional enrichment analysis. According to the $\mathrm{GO}$ enrichment analysis, these mRNAs were involved in the regulation of biologica processes, cellular components, and molecular functions (Fig. 4). The pie graph shows that 151 mRNAs were related to singleorganism cellular processes in the "biological process" term, and 168 mRNAs were included in cell parts in the "cellular component" classification. Moreover, the "molecular function" category of GO terms showed that 152 mRNAs mainly played a role in protein binding, ion binding, and catalytic activity. Pathways modulated by relevant gene targets of the differentially expressed miRNAs of negatively correlated miRNA-mRNA pairs were determined using KEGG pathways. All the significant target pathways for the negatively correlated miRNA-mRNA pairs are presented in Fig. 5. Upregulation of negative miRNA-mRNA correlation was related to focal adhesion, Rap1 signaling, regulation of actin cytoskeleton, and AMP-activated protein kinase signaling pathways, whereas downregulation of negative miRNAmRNA correlation was shown to be related to proteoglycans in cancer, central carbon metabolism in cancer, cell adhesion molecules, and cytokine-cytokine receptor interaction (Table 6).

\section{Discussion}

In this study, using the human astroglioma cell line CRTMG, we investigated the effect of necrosis on the miRNA and mRNA expression profiles and further examined the miRNA-mRNA correlations. When CRT-MG cells were 
Table 3. The top 20 most differentially upregulated and downregulated mRNAs in necrotic cell-treated CRT-MG cells

\begin{tabular}{|c|c|c|c|}
\hline & mRNA & Fold change & GBM \\
\hline \multirow{20}{*}{ Upregulated mRNAs (top 20 out of 508) } & IL8 & 192.74 & {$[5,28-31]$} \\
\hline & IL1B & 143.94 & - \\
\hline & CSF3 & 142.34 & [32] \\
\hline & CCL20 & 78.29 & [33] \\
\hline & CXCL2 & 55.65 & {$[34,35]$} \\
\hline & PI3 & 46.88 & - \\
\hline & MMP1 & 46.52 & - \\
\hline & CSF2 & 44.52 & [36] \\
\hline & SAA1 & 31.04 & [37] \\
\hline & C3 & 29.79 & {$[38,39]$} \\
\hline & LCN2 & 29.44 & - \\
\hline & IER3 & 29.03 & - \\
\hline & CXCL3 & 25.64 & [40] \\
\hline & IL1A & 22.20 & - \\
\hline & SOD2 & 21.54 & - \\
\hline & MMP9 & 19.76 & [41-44] \\
\hline & G0S2 & 19.44 & - \\
\hline & $S A A 2$ & 17.82 & [37] \\
\hline & MRGPRX3 & 14.09 & - \\
\hline & TNF & 13.83 & {$[45-47]$} \\
\hline \multirow[t]{20}{*}{ Downregulated mRNAs (top 20 out of 379) } & $C R Y A B$ & -16.56 & - \\
\hline & TNNC1 & -10.24 & - \\
\hline & HSD17B2 & -10.10 & - \\
\hline & TMEM130 & -8.52 & - \\
\hline & ID2 & -8.37 & [48] \\
\hline & POSTN & -7.82 & - \\
\hline & COL3A1 & -7.74 & - \\
\hline & NUPR1 & -7.74 & - \\
\hline & SCNN1A & -7.50 & - \\
\hline & LGR6 & -7.44 & - \\
\hline & EDN2 & -7.31 & - \\
\hline & HOTS & -7.16 & - \\
\hline & PCP4 & -7.06 & - \\
\hline & GPNMB & -6.91 & [49] \\
\hline & ANKRD1 & -6.70 & - \\
\hline & $A B C G 1$ & -6.28 & - \\
\hline & HSPB3 & -6.21 & - \\
\hline & COL26A1 & -6.05 & - \\
\hline & $A L P P$ & -5.80 & - \\
\hline & MAP2 & -5.79 & [50] \\
\hline
\end{tabular}

exposed to necrotic CRT-MG cells, we found that 55 miRNAs were upregulated and 51 were downregulated at a significantly different expression level, with a 2-fold change as a cut off. Among them, 11 miRNAs that had a negative miRNA-mRNA correlation value of $\mathrm{p}<0.05$ by the hypergeometric test were screened, and target mRNAs were analyzed by GO enrichment analysis. Using the KEGG database, we also found that several pathways that were activated by the necrotic cell treatment were modulated by relevant gene targets of differentially expressed miRNAs with negative miRNA-mRNA correlation.

Exposure to necrotic cells induced the dysregulation of several miRNAs and the differential expression of mRNAs in the CRT-MG cells. The examination revealed that miR- 


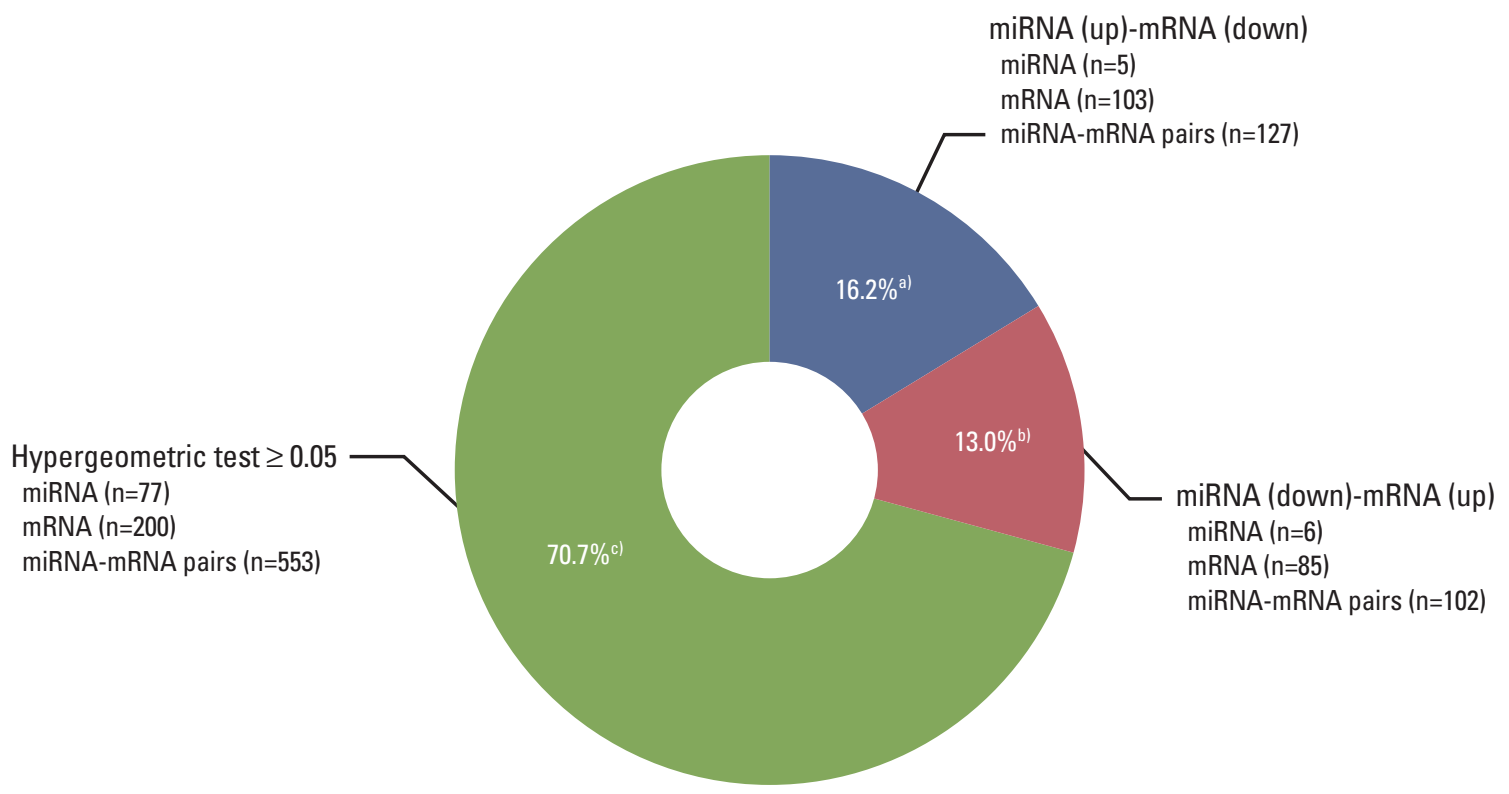

Fig. 3. Pie chart representing the distribution of negatively correlated miRNA-mRNA pairs. Pie chart depicting the distribution of negatively correlated miRNA-mRNA pairs within the three color-coded groups. Eighty-eight miRNAs were found to have at least one negatively regulated miRNA-mRNA pair for significant mRNAs, and 11 miRNAs a negative correlation with $\mathrm{p}<0.05$ by the hypergeometric test. ${ }^{\text {a) }}$ Upregulated miRNAs-downregulated mRNAs in necrotic cell-treated CRT-MG with $\mathrm{p}<0.05$ by the hypergeometric test, ${ }^{\text {b) }}$ Downregulated miRNAs-upregulated mRNAs in necrotic cell-treated CRT-MG with $\mathrm{p}<0.05$ by the hypergeometric test, ${ }^{\mathrm{c}}$ Negatively regulated miRNA-mRNA pairs with $\mathrm{p} \geq 0.05$ by the hypergeometric test.

Table 4. Summary of the miRNA-mRNA integrative genomic analysis

\begin{tabular}{|c|c|c|c|c|c|}
\hline & \multirow{2}{*}{$\begin{array}{l}\text { No. of } \\
\text { significant } \\
\text { miRNAs } \\
(|\mathrm{fc}| \geq 2)\end{array}$} & \multirow{2}{*}{$\begin{array}{c}\text { No. of } \\
\text { significant } \\
\text { mRNAs } \\
(|\mathrm{fc}| \geq 2)\end{array}$} & \multirow{2}{*}{ No. of miRNAs } & \multicolumn{2}{|c|}{$\begin{array}{l}\text { No. of miRNAs } \\
\text { (at negative relationship) }\end{array}$} \\
\hline & & & & $\begin{array}{c}\text { Hypergeometric } \\
\text { test }<0.05\end{array}$ & $\begin{array}{l}\text { Hypergeometric } \\
\text { test } \geq 0.05\end{array}$ \\
\hline Control vs. necrotic cell-treated & 106 & 887 & 88 & 11 & 77 \\
\hline
\end{tabular}

a)At least 1 miRNA-mRNA negative regulated pairs in significant mRNAs.

4492 was increased and showed negative regulation with 60 downregulated target mRNAs through the necrotic cell treatment (Table 5). Since the effect of miR-4492 on brain cancer is poorly understood at present, our results suggest that miR4492 might be a novel prognostic marker of GBM that is activated by necrosis. The increased miR-4492 expression negatively regulated COL2A1 and CNR1 mRNAs, which are related to focal adhesion and Rap1 signaling. Rap1 is a small GTPase that regulates cell adhesion, cell-cell junction formation and cell polarity thought mitogen-activated protein kinase. Cell adhesion signaling is known to modulate cell proliferation, survival, and migration in several cancers, suggesting that this signaling is important for the development of new therapeutic targets [51-53]. We confirmed by RT-PCR that the expression levels of the COL2A1 and CNR1 genes were decreased by the treatment of necrotic cells for validation of mRNA sequencing data (Fig. 2D).

Previous studies have provided evidence of multiple relationships between miRNAs and their target genes in cancer $[14,54]$. It appears that the dysregulation of miRNA profiles 
Table 5. Integrative genomic analysis of 11 miRNA target genes

\begin{tabular}{|c|c|c|c|}
\hline $\begin{array}{l}\text { Significant } \\
\text { miRNA }\end{array}$ & Count & $\begin{array}{l}\text { Hypergeometric } \\
\text { test (p-value) }\end{array}$ & Gene \\
\hline \multicolumn{4}{|c|}{ miRNA (up)-mRNA (down) } \\
\hline hsa-miR-4492 & 60 & 0.006 & $\begin{array}{l}\text { SCNN1A, EDN2, COL26A1, ALPP, MFAP4, ALDH3B1, IGFBP5, } \\
\text { PPL, RGS5, KCNIP1, OLFML2A, SAMD11, LYPD1, CNR1,PKP2, } \\
\text { SYT12, FOXS1, LOXL4, IFITM10, ITGB4, SREBF1, PDGFRB, } \\
\text { CADM3, MPPED2, FIBCD1, PIK3R3, GPX3, FAM65B, TPD52L1, } \\
\text { SLC48A1, KCNH2, LYNX1, WLS, SLC7A8, COL2A1, TOM1L2, } \\
\text { SMAD7, C10orf54, HDAC5, PLEKHB1, RAB26, ST6GALNAC2, } \\
\text { BOK, CAMKK1, RHOB, ELFN2, WDR86, SEMA3F, HSPB6, } \\
\text { BCAM, CACFD1, LMCD1, JDP2, CAPN6, FAIM2, SPTB, SYT15, } \\
\text { SLC25A23, EFNA2, GLIS2 }\end{array}$ \\
\hline hsa-miR-185-5p & 25 & 0.007 & $\begin{array}{l}\text { POSTN, LGR6, PCP4, GPNMB, ABCG1, LBH, CSDC2, IGFBP5, } \\
\text { FAM198B, CADM3, HOPX, UNC5C, RAB11FIP1, GPX3, FAM65B, } \\
\text { TMEM139, BTBD3, UBE2QL1, PTPN13, HDAC5, PLEKHB1, BMF, } \\
\text { SORL1, FAIM2, SPTB }\end{array}$ \\
\hline hsa-miR-3609 & 19 & 0.043 & $\begin{array}{l}\text { SDC2, PDE5A, MYLIP, CDH6, TYRP1, SCD, GPC4, RAB11FIP1, } \\
\text { FAM65B, SLC48A1, PDGFC, GMPR, ABCB5, UBE2QL1, PTPN13, } \\
\text { EIF4A2, SYT15, PFN2, PCSK2 }\end{array}$ \\
\hline hsa-miR-139-5p & 13 & 0.007 & $\begin{array}{l}\text { MAP2, IGFBP5, THBS1, AQP1, SESN3, GPM6A, RAB11FIP1, } \\
\text { NDRG2, GULP1, JAKMIP2, JDP2, IQCJ-SCHIP1, PFN2 }\end{array}$ \\
\hline hsa-miR-3656 & 10 & 0.010 & $\begin{array}{l}\text { NXN, LYPD1, CADM3, SLC48A1, ZNF503, TOM1L2, ATP1B2, } \\
\text { HSPB6, FAIM2, LDB1 }\end{array}$ \\
\hline \multicolumn{4}{|c|}{ miRNA (down)-mRNA (up) } \\
\hline hsa-miR-30b-3p & 39 & 0.000 & $\begin{array}{l}\text { CD82, ICAM1, MEFV, TNFRSF9, CX3CL1, RELT, TMEM52B, } \\
\text { WNT7B, CDCP1, LRRC55, APLN, PTGES, NTN1, CORO2B, } \\
\text { DTX4, PIK3CD, CSF1, ZWINT, SPRED3, ARNTL2, PDPN, } \\
\text { ST3GAL4, CD34, NTSR1, SLC43A2, SAPCD2, NEK2, SH2B3, } \\
\text { TSPAN18, OAS3, MOB3A, IQGAP3, SLC11A2, CORO1A, KLRC3, } \\
\text { NCEH1, KIF18B, CYP1A2, JAM2 }\end{array}$ \\
\hline hsa-miR-874-5p & 19 & 0.001 & $\begin{array}{l}\text { CHI3L1, CD82, ICAM1, CX3CL1, TNFAIP2, RELT, KIF21B, } \\
\text { WNT7B, SDC4, PREX1, ITGA5, SLC16A3, CD34, ITGA2, } \\
\text { MFSD2A, HMGA1, PFKL, GPR37L1, RAB43 }\end{array}$ \\
\hline hsa-miR-2682-5p & 13 & 0.031 & $\begin{array}{l}\text { ADORA2A, LRRC55, NDRG1, HPCAL1, LCP1, NETO1, PHACTR1, } \\
\text { ABLIM3, LRIG1, TSPAN18, PAPSS2, FAM219A, RAB43 }\end{array}$ \\
\hline hsa-miR-138-5p & 13 & 0.03 & $\begin{array}{l}\text { LCN2, CLEC1A, NTN1, DTX4, PDPN, WWC1, FAM83D, CD34, } \\
\text { SLC16A2, SH2B3, UNC5A, FRMD4A, SLC7A2 }\end{array}$ \\
\hline hsa-miR-874-3p & 11 & 0.0191 & $\begin{array}{l}\text { IKBKE, RRM2, DTX4, TCF19, FAM107B, AGTRAP, AFAP1L1, } \\
\text { RAB13, FLT1, FAM19A3, RAB27A }\end{array}$ \\
\hline hsa-miR-3613-5p & 7 & 0.018 & MT2A, MPP4, MT1X, RRM2, PAPSS2, CCDC71L, PDK1 \\
\hline
\end{tabular}

could serve as an effective diagnostic and prognostic biomarker. In our systems, we found the significant dysregulation of the expression of 11 miRNAs in necrotic cell-treated CRT-MG cells compared with untreated cells. Similar to previous reports about GBM, we found that miR-146a-5p and miR-1246 were upregulated in the treated CRT-MG cells $[24,25]$. While the expression level and function of miRNAs in glioblastoma have been extensively studied by several groups, the effects of necrosis/necrotic cells on miRNA and mRNA expression and necrosis-related cellular pathways have not been investigated. Further studies are needed to identify cellular pathway within necrosis-related GBM. We were also able to identify the dysregulation of novel miRNAs in the treated astroglioma cells. In particular, the miR-4792 level was increased by 149 -fold, and miR-3609 by 60 -fold, in the presence of necrotic cells, suggesting that these miRNAs 

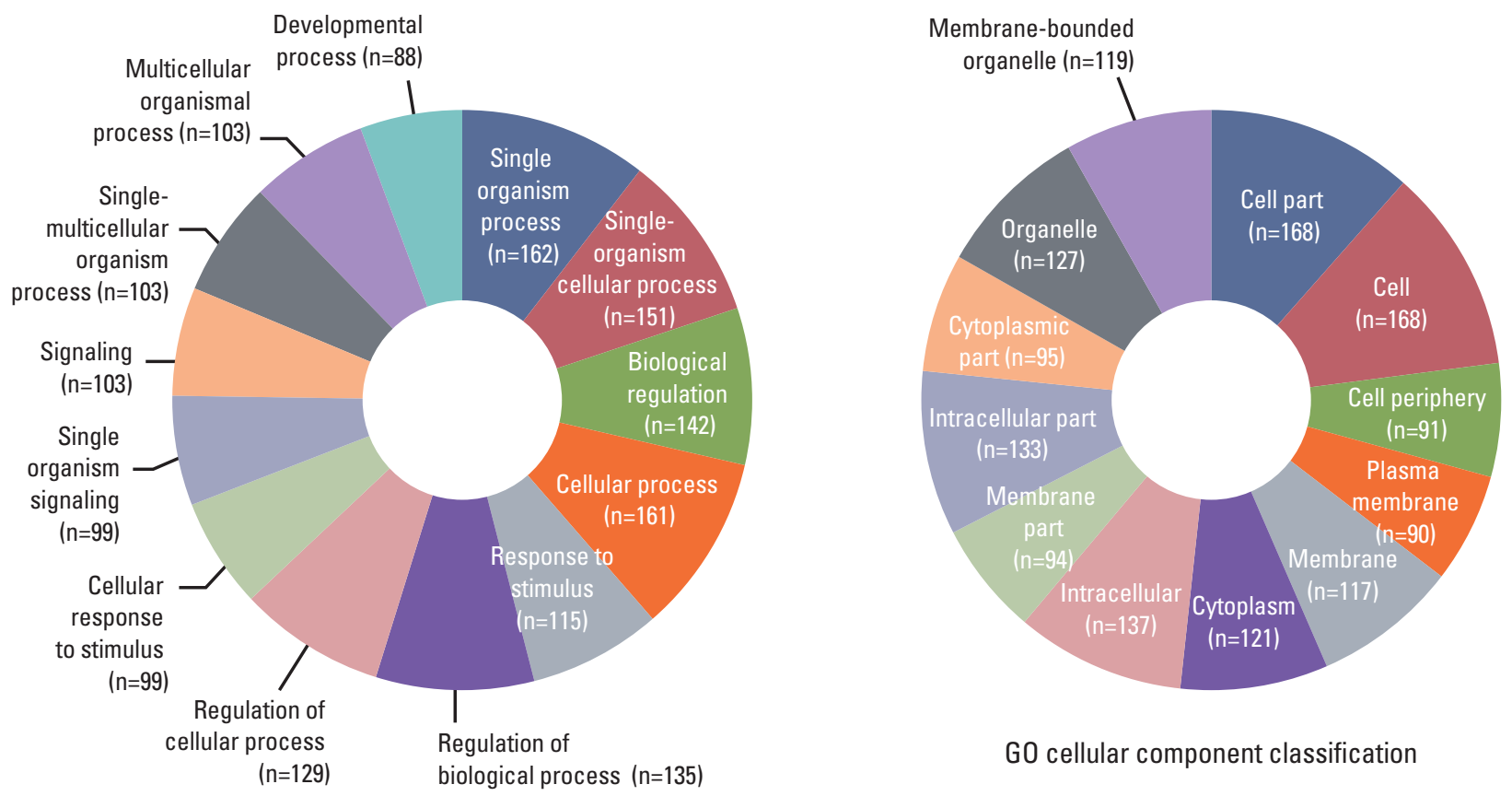

GO cellular component classification

GO biological process classification

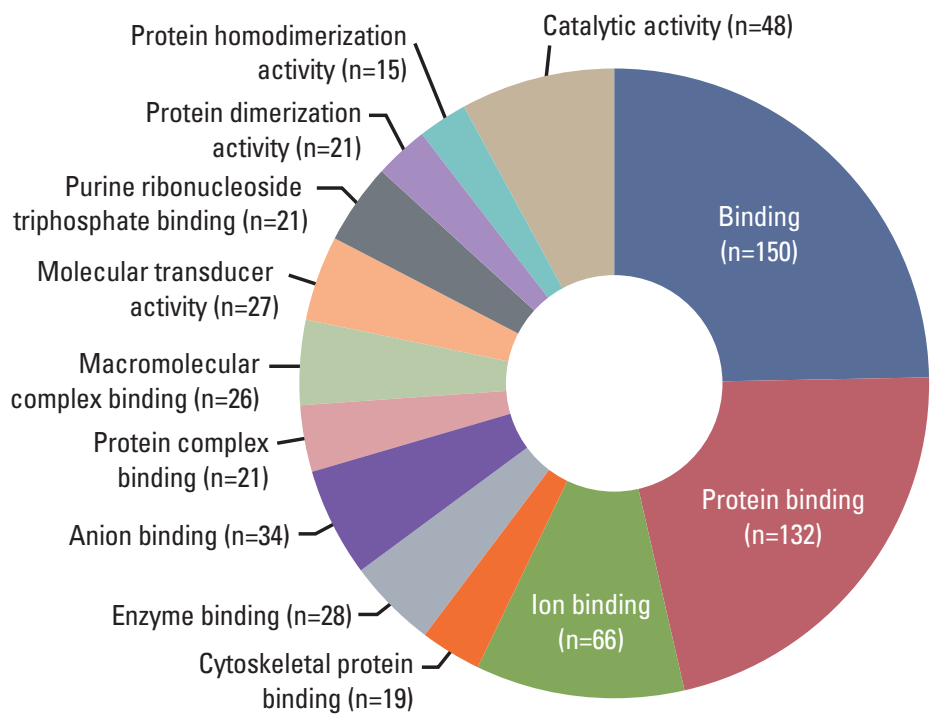

GO molecular function classification

Fig. 4. Gene Ontology (GO) enrichment analysis for negatively correlated miRNA-mRNA. The 188 genes that were upregulated and downregulated in necrotic cell-treated CRT-MG cells, with $p<0.05$ by the hypergeometric test, were subjected to $\mathrm{GO}$ functional enrichment analysis. To study the regulatory effects of the significant negatively correlated miRNA-mRNA pairs, and to further explore the function of the predicted target genes. These mRNAs were included in the biological process, cell component, and molecular function classifications. 


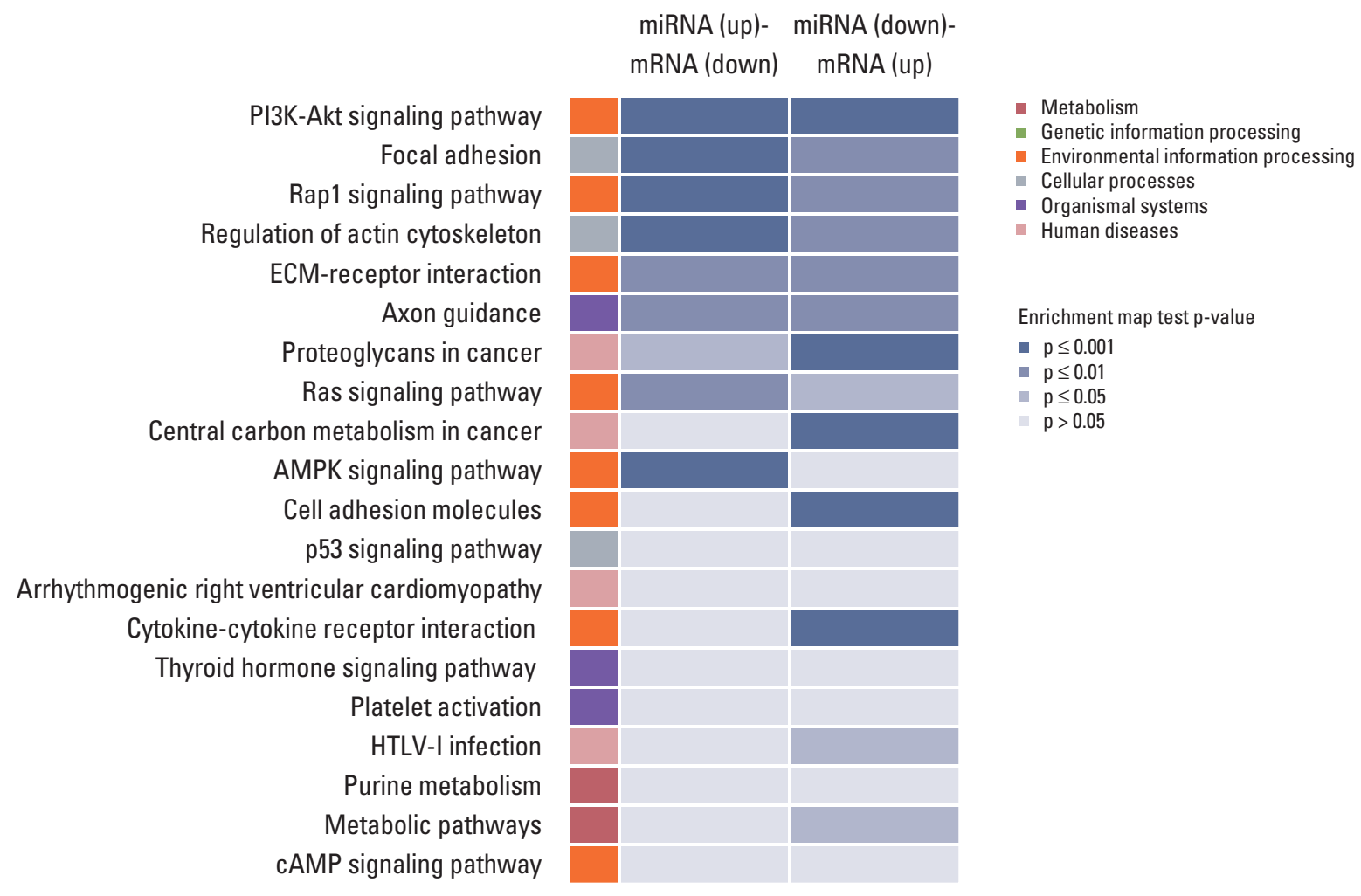

Fig. 5. Kyoto Encyclopedia of Genes and Genomes (KEGG) pathway analysis for negatively correlated miRNA-mRNA pairs. The 188 genes that were upregulated and downregulated in necrotic cell-treated CRT-MG cells, with $p<0.05$ by the hypergeometric test, were subjected to KEGG database analysis. These mRNAs were related to various biological pathways of metabolism (red), genetic information (green), environmental information (orange), cellular processes (gray), organismal system (purple), and human diseases (pink). The colors in the enrichment map represent the significant p-values of the geneset enrichment, with high significant values $(\mathrm{p} \leq 0.001)$ being colored in blue shade. PI3K, phosphoinositide 3-kinase; ECM, extracellular matrix; AMPK, AMP-activated protein kinase.

Table 6. KEGG pathway analysis of the genes obtained from negatively correlated miRNA-mRNA pairs

\begin{tabular}{|c|c|c|c|}
\hline Map name & Count & p-value & Gene \\
\hline \multicolumn{4}{|l|}{ miRNA (up)-mRNA (down) } \\
\hline Focal adhesion & 6 & $1.56 \mathrm{E}-06$ & COL2A1, ITGB4, PDGFRB, PDGFC, THBS1, PIK3R3 \\
\hline Rap1 signaling pathway & 7 & 4.98E-08 & CNR1, EFNA2, PDGFRB, PFN2, PDGFC, THBS1, PIK3R3 \\
\hline Regulation of actin cytoskeleton & 5 & 5.13E-05 & ITGB4, PDGFRB, PFN2, PDGFC, PIK3R3 \\
\hline AMPK signaling pathway & 4 & 0.000228 & SCD, SREBF1, CAMKK1, PIK3R3 \\
\hline \multicolumn{4}{|l|}{ miRNA (down)-mRNA (up) } \\
\hline Proteoglycans in cancer & 5 & 7.65E-05 & ITGA2, ITGA5, PIK3CD, SDC4, WNT7B \\
\hline Central carbon metabolism in cancer & 4 & 6.13E-05 & PDK1, PFKL, PIK3CD, SLC16A3 \\
\hline Cell adhesion molecules & 4 & 0.000559 & ICAM1, JAM2, SDC4, CD34 \\
\hline Cytokine-cytokine receptor interaction & 5 & 0.000205 & CSF1, FLT1, TNFRSF9, CX3CL1, RELT \\
\hline
\end{tabular}

KEGG, Kyoto Encyclopedia of Genes and Genomes. 
could be potential candidates for the detection of necrosis.

Using NGS, we confirmed that not only miRNA expression but also mRNA expression was significantly modulated by necrotic cells in CRT-MG cells, as controlled by a variety of gene regulatory factors, including transcription factors and miRNAs. Incubation with necrotic cells induced the dysregulation of 887 mRNAs (Fig. 2). Among them, 188 mRNAs had a negative correlation with 11 miRNAs. For example, the dysregulation of PFN2, WNT7B, PFKL, PDK1, and LCN2 mRNAs was negatively correlated with miR-3609, miR-30b$3 p$, miR-874-5p, miR-3613-5p, and miR-138-5p. On the other hand, the expression levels of $I L-8, I L-1 \beta, C S F 3, C C L 20$, and CXCL2 mRNAs, which were included within the 887 mRNAs deregulated by necrotic cell treatment, were remarkably increased (Table 3); however, we did not find significant negative correlations between these mRNAs and their corresponding miRNAs. Recently, we reported that when GBM cells are exposed to and stimulated by necrotic cells, activation of the transcription factors nuclear factor $\mathrm{\kappa B}$ and activator protein 1 and their binding to the interleukin 8 (IL8) promoter were induced, leading to enhanced IL 8 mRNA expression and protein secretion in GBM cells [5]. These results imply that necrotic cells had a regulatory effect on mRNA expression by both miRNA-mediated gene regulatory and transcription factor-mediated events.

It has been reported that negatively regulated miRNAmRNA pairs have a significant effect on the prognosis of cancer $[55,56]$. In this study, we used KEGG to identify pathways that were related to negative miRNA-mRNA correlation. Consequently, we identified key miRNAs such as miR-874$5 \mathrm{p}$ and miR-30b-3p that were implicated in proteoglycan, central carbon metabolism, and cytokine-cytokine receptor interaction pathways, based on their target genes, such as PIK3CD and CX3CL1 (Table 6). PIK3CD is a phosphoinositide 3 kinase class I isoform that is found in a number of immune cells. In metastatic colorectal carcinoma and GBM,
PIK3CD is upregulated via the downregulation of miRNA, which regulates the Akt pathway [57,58]. Moreover, the chemokine ligand CX3CL1 (also known as fractalkine) is expressed mainly in monocytes during inflammatory conditions [59]. Previous studies have demonstrated that CX3CL1 acts as a positive modulator of breast cancer, and also functions as an inflammatory mediator for communication between neurons, glia, and microglia during inflammation and neuro degeneration [60-62]. We identified the negatively regulated miR-874-5p and miR-30b-3p/PIK3CD and CX3CL1 pairs, which were implicated in proteoglycan and cytokinecytokine receptor interaction signaling pathways, suggesting them to be novel prognostic markers in GBM that are exposed and activated by necrosis. Further study will be required to address the clinical relevance of these miRNAs and mRNAs and their putative role on necrosis-related molecular pathways for the development of novel diagnostic and prognostic biomarkers.

In conclusion, our study demonstrate that when GBM cells were exposed to and stimulated by necrotic cells, the expression profiles of miRNA and mRNA were significantly dysregulated. This is the first study to address the effect of necrotic cells on miRNA-mRNA expression and association in GBM cells. The data implicated several miRNAs including miR-4492 might be a novel prognostic marker of GBM that is activated by necrosis.

\section{Conflicts of Interest}

Conflict of interest relevant to this article was not reported.

\section{Acknowledgments}

This work was supported by a National Research Foundation of Korea (NRF) grant funded by the Korean government (MSIP) Grant 2010-0027945 and by NRF-2016R1A2B4016376.

\section{References}

1. Scheithauer BW. Development of the WHO classification of tumors of the central nervous system: a historical perspective. Brain Pathol. 2009;19:551-64.

2. Nakada M, Kita D, Watanabe T, Hayashi Y, Teng L, Pyko IV, et al. Aberrant signaling pathways in glioma. Cancers (Basel). 2011;3:3242-78.

3. Hammoud MA, Sawaya R, Shi W, Thall PF, Leeds NE. Prognostic significance of preoperative MRI scans in glioblastoma multiforme. J Neurooncol. 1996;27:65-73.

4. Raza SM, Lang FF, Aggarwal BB, Fuller GN, Wildrick DM,
Sawaya R. Necrosis and glioblastoma: a friend or a foe? A review and a hypothesis. Neurosurgery. 2002;51:2-12.

5. Ahn SH, Park H, Ahn YH, Kim S, Cho MS, Kang JL, et al. Necrotic cells influence migration and invasion of glioblastoma via NF-kappaB / AP-1-mediated IL-8 regulation. Sci Rep. 2016;6:24552.

6. Barboriak DP, Provenzale JM. Evaluation of software for registration of contrast-enhanced brain MR images in patients with glioblastoma multiforme. AJR Am J Roentgenol. 2002; 179:245-50. 
7. Inui M, Martello G, Piccolo S. MicroRNA control of signal transduction. Nat Rev Mol Cell Biol. 2010;11:252-63.

8. Que T, Song Y, Liu Z, Zheng S, Long H, Li Z, et al. Decreased miRNA-637 is an unfavorable prognosis marker and promotes glioma cell growth, migration and invasion via direct targeting Akt1. Oncogene. 2015;34:4952-63.

9. Hu N, Zhang J, Cui W, Kong G, Zhang S, Yue L, et al. miR$520 \mathrm{~b}$ regulates migration of breast cancer cells by targeting hepatitis B X-interacting protein and interleukin-8. J Biol Chem. 2011;286:13714-22.

10. LeBlanc VC, Morin P. Exploring miRNA-associated signatures with diagnostic relevance in glioblastoma multiforme and breast cancer patients. J Clin Med. 2015;4:1612-30.

11. Chiosea S, Jelezcova E, Chandran U, Acquafondata M, McHale T, Sobol RW, et al. Up-regulation of dicer, a component of the microRNA machinery, in prostate adenocarcinoma. Am J Pathol. 2006;169:1812-20.

12. Qu JQ, Yi HM, Ye X, Zhu JF, Yi H, Li LN, et al. MiRNA-203 reduces nasopharyngeal carcinoma radioresistance by targeting IL8 / AKT signaling. Mol Cancer Ther. 2015;14:2653-64.

13. Jansson MD, Lund AH. MicroRNA and cancer. Mol Oncol. 2012;6:590-610.

14. Chen B, Li H, Zeng X, Yang P, Liu X, Zhao X, et al. Roles of microRNA on cancer cell metabolism. J Transl Med. 2012; 10:228.

15. Di Leva G, Garofalo M, Croce CM. MicroRNAs in cancer. Annu Rev Pathol. 2014;9:287-314.

16. Dong L, Li Y, Han C, Wang X, She L, Zhang H. miRNA microarray reveals specific expression in the peripheral blood of glioblastoma patients. Int J Oncol. 2014;45:746-56.

17. Xia Z, Liu F, Zhang J, Liu L. Decreased expression of miRNA204-5p contributes to glioma progression and promotes glioma cell growth, migration and invasion. PLoS One. 2015; 10:e0132399.

18. Fabbri E, Brognara E, Montagner G, Ghimenton C, Eccher A, Cantu C, et al. Regulation of IL-8 gene expression in gliomas by microRNA miR-93. BMC Cancer. 2015;15:661.

19. Mucaj V, Lee SS, Skuli N, Giannoukos DN, Qiu B, EisingerMathason TS, et al. MicroRNA-124 expression counteracts pro-survival stress responses in glioblastoma. Oncogene. 2015; 34:2204-14.

20. Basu S, Binder RJ, Suto R, Anderson KM, Srivastava PK. Necrotic but not apoptotic cell death releases heat shock proteins, which deliver a partial maturation signal to dendritic cells and activate the NF-кB pathway. Int Immunol. 2000;12: 1539-46.

21. Livak KJ, Schmittgen TD. Analysis of relative gene expression data using real-time quantitative PCR and the $2^{-\Delta \Delta C \mathrm{CT}}$ method. Methods. 2001;25:402-8.

22. Harris MA, Clark J, Ireland A, Lomax J, Ashburner M, Foulger $\mathrm{R}$, et al. The Gene Ontology (GO) database and informatics resource. Nucleic Acids Res. 2004;32:D258-61.

23. Kanehisa M, Goto S, Kawashima S, Nakaya A. The KEGG databases at GenomeNet. Nucleic Acids Res. 2002;30:42-6.

24. Xu G, Li JY. Differential expression of PDGFRB and EGFR in microvascular proliferation in glioblastoma. Tumour Biol.
2016;37:10577-86.

25. Li P, Teng F, Gao F, Zhang M, Wu J, Zhang C. Identification of circulating microRNAs as potential biomarkers for detecting acute ischemic stroke. Cell Mol Neurobiol. 2015;35:433-47.

26. Plaisier CL, O'Brien S, Bernard B, Reynolds S, Simon Z, Toledo $\mathrm{CM}$, et al. Causal mechanistic regulatory network for glioblastoma deciphered using systems genetics network analysis. Cell Syst. 2016;3:172-86.

27. Liang ML, Hsieh TH, Ng KH, Tsai YN, Tsai CF, Chao ME, et al. Downregulation of miR-137 and miR-6500-3p promotes cell proliferation in pediatric high-grade gliomas. Oncotarget. 2016;7:19723-37.

28. Munoz L, Yeung YT, Grewal T. Oncogenic Ras modulates p38 MAPK-mediated inflammatory cytokine production in glioblastoma cells. Cancer Biol Ther. 2016;17:355-63.

29. Ouchi R, Okabe S, Migita T, Nakano I, Seimiya H. Senescence from glioma stem cell differentiation promotes tumor growth. Biochem Biophys Res Commun. 2016;470:275-81.

30. Zhang B, Shi L, Lu S, Sun X, Liu Y, Li H, et al. Autocrine IL-8 promotes F-actin polymerization and mediate mesenchymal transition via ELMO1-NF-kappaB-Snail signaling in glioma. Cancer Biol Ther. 2015;16:898-911.

31. Zhou J, Yi L, Ouyang Q, Xu L, Cui H, Xu M. Neurotensin signaling regulates stem-like traits of glioblastoma stem cells through activation of IL-8 / CXCR1 / STAT3 pathway. Cell Signal. 2014;26:2896-902.

32. Bertaut A, Truntzer C, Madkouri R, Kaderbhai CG, Derangere $\mathrm{V}$, Vincent J, et al. Blood baseline neutrophil count predicts bevacizumab efficacy in glioblastoma. Oncotarget. 2016;7: 70948-58.

33. Wang L, Qin H, Li L, Zhang Y, Tu Y, Feng F, et al. Overexpression of CCL20 and its receptor CCR6 predicts poor clinical prognosis in human gliomas. Med Oncol. 2012;29:3491-7.

34. Brandenburg S, Muller A, Turkowski K, Radev YT, Rot S, Schmidt C, et al. Resident microglia rather than peripheral macrophages promote vascularization in brain tumors and are source of alternative pro-angiogenic factors. Acta Neuropathol. 2016;131:365-78.

35. Bruyere C, Mijatovic T, Lonez C, Spiegl-Kreinecker S, Berger W, Kast RE, et al. Temozolomide-induced modification of the CXC chemokine network in experimental gliomas. Int J Oncol. 2011;38:1453-64.

36. Sielska M, Przanowski P, Wylot B, Gabrusiewicz K, Maleszewska M, Kijewska M, et al. Distinct roles of CSF family cytokines in macrophage infiltration and activation in glioma progression and injury response. J Pathol. 2013;230:310-21.

37. Knebel FH, Albuquerque RC, Massaro RR, Maria-Engler SS, Campa A. Dual effect of serum amyloid A on the invasiveness of glioma cells. Mediators Inflamm. 2013;2013:509089.

38. Bouwens TA, Trouw LA, Veerhuis R, Dirven CM, Lamfers $\mathrm{ML}, \mathrm{Al}-\mathrm{Khawaja} \mathrm{H}$. Complement activation in glioblastoma multiforme pathophysiology: evidence from serum levels and presence of complement activation products in tumor tissue. J Neuroimmunol. 2015;278:271-6.

39. Li M, Bolduc AR, Hoda MN, Gamble DN, Dolisca SB, Bolduc $\mathrm{AK}$, et al. The indoleamine 2,3-dioxygenase pathway controls 
complement-dependent enhancement of chemo-radiation therapy against murine glioblastoma. J Immunother Cancer. 2014;2:21.

40. Kammerer R, Buchner A, Palluch P, Pongratz T, Oboukhovskij $\mathrm{K}$, Beyer $\mathrm{W}$, et al. Induction of immune mediators in glioma and prostate cancer cells by non-lethal photodynamic therapy. PLoS One. 2011;6:e21834.

41. Li Q, Chen B, Cai J, Sun Y, Wang G, Li Y, et al. Comparative analysis of matrix metalloproteinase family members reveals that MMP9 predicts survival and response to temozolomide in patients with primary glioblastoma. PLoS One. 2016;11: e0151815.

42. Joseph JV, van Roosmalen IA, Busschers E, Tomar T, Conroy S, Eggens-Meijer E, et al. Serum-induced differentiation of glioblastoma neurospheres leads to enhanced migration/ invasion capacity that is associated with increased MMP9. PLoS One. 2015;10:e0145393.

43. Musumeci G, Magro G, Cardile V, Coco M, Marzagalli R, Castrogiovanni $\mathrm{P}$, et al. Characterization of matrix metalloproteinase-2 and -9, ADAM-10 and N-cadherin expression in human glioblastoma multiforme. Cell Tissue Res. 2015;362: 45-60.

44. Wang F, Xiao W, Sun J, Han D, Zhu Y. MiRNA-181c inhibits EGFR-signaling-dependent MMP9 activation via suppressing Akt phosphorylation in glioblastoma. Tumour Biol. 2014;35: 8653-8.

45. Hwang JS, Jung EH, Kwon MY, Han IO. Glioma-secreted soluble factors stimulate microglial activation: The role of interleukin-1beta and tumor necrosis factor-alpha. J Neuroimmunol. 2016;298:165-71.

46. Kryvdiuk IV, Minchenko DO, Hlushchak NA, Ratushna OO, Karbovskyi LL, Minchenko OH. Inhibition of IRE1 modifies effect of glucose deprivation on the expression of TNF $\alpha$ related genes in U87 glioma cells. Ukr Biochem J. 2015;87: 36-51.

47. Kore RA, Abraham EC. Inflammatory cytokines, interleukin1 beta and tumor necrosis factor-alpha, upregulated in glioblastoma multiforme, raise the levels of CRYAB in exosomes secreted by U373 glioma cells. Biochem Biophys Res Commun. 2014;453:326-31.

48. Rahme GJ, Zhang Z, Young AL, Cheng C, Bivona EJ, Fiering $\mathrm{SN}$, et al. PDGF engages an E2F-USP1 signaling pathway to support ID2-mediated survival of proneural glioma cells. Cancer Res. 2016;76:2964-76.

49. Bao G, Wang N, Li R, Xu G, Liu P, He B. MiR-508-5p inhibits the progression of glioma by targeting glycoprotein nonmetastatic melanoma B. Neurochem Res. 2016;41:1684-90.
50. Qu J, Rizak JD, Fan Y, Guo X, Li J, Huma T, et al. Establishment and partial characterization of a human tumor cell line, GBM-HSF, from a glioblastoma multiforme. Hum Cell. 2014;27:129-36.

51. McLean GW, Carragher NO, Avizienyte E, Evans J, Brunton VG, Frame MC. The role of focal-adhesion kinase in cancer: a new therapeutic opportunity. Nat Rev Cancer. 2005;5:505-15.

52. Totoki Y, Yoshida A, Hosoda F, Nakamura H, Hama N, Ogura $\mathrm{K}$, et al. Unique mutation portraits and frequent COL2A1 gene alteration in chondrosarcoma. Genome Res. 2014;24:1411-20.

53. Bedoya F, Meneu JC, Macias MI, Moreno A, Enriquez-De-Salamanca R, Gonzalez EM, et al. Mutation in CNR1 gene and VEGF expression in esophageal cancer. Tumori. 2009;95:68-75.

54. Plaisier CL, Pan M, Baliga NS. A miRNA-regulatory network explains how dysregulated miRNAs perturb oncogenic processes across diverse cancers. Genome Res. 2012;22: 2302-14.

55. Zhou X, Xu X, Wang J, Lin J, Chen W. Identifying miRNA/ mRNA negative regulation pairs in colorectal cancer. Sci Rep. 2015;5:12995.

56. Thurnherr T, Mah WC, Lei Z, Jin Y, Rozen SG, Lee CG. Differentially Expressed miRNAs in hepatocellular carcinoma target genes in the genetic information processing and metabolism pathways. Sci Rep. 2016;6:20065.

57. Zhong M, Bian Z, Wu Z. miR-30a suppresses cell migration and invasion through downregulation of PIK3CD in colorectal carcinoma. Cell Physiol Biochem. 2013;31:209-18.

58. Shi Y, Chen C, Zhang X, Liu Q, Xu JL, Zhang HR, et al. Primate-specific miR-663 functions as a tumor suppressor by targeting PIK3CD and predicts the prognosis of human glioblastoma. Clin Cancer Res. 2014;20:1803-13.

59. Jones BA, Beamer M, Ahmed S. Fractalkine/CX3CL1: a potential new target for inflammatory diseases. Mol Interv. 2010;10: 263-70.

60. Tardaguila M, Mira E, Garcia-Cabezas MA, Feijoo AM, Quintela-Fandino M, Azcoitia I, et al. CX3CL1 promotes breast cancer via transactivation of the EGF pathway. Cancer Res. 2013;73:4461-73.

61. Ferretti E, Pistoia V, Corcione A. Role of fractalkine/CX3CL1 and its receptor in the pathogenesis of inflammatory and malignant diseases with emphasis on B cell malignancies. Mediators Inflamm. 2014;2014:480941.

62. Marchesi F, Locatelli M, Solinas G, Erreni M, Allavena P, Mantovani A. Role of CX3CR1/CX3CL1 axis in primary and secondary involvement of the nervous system by cancer. J Neuroimmunol. 2010;224:39-44. 